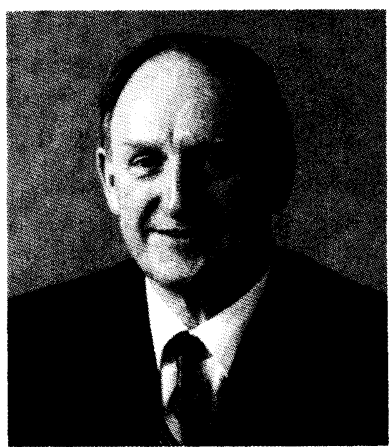

\section{A Tribute to Rudolf Kingslake on His 90th Birthday}

It has been a great pleasure for me to work with Dr. Arthur Cox on this tribute to Rudolf Kingslake and his contributions to lens design. It was Arthur Cox who suggested the idea of a special section of contributions from some of those who have been closely associated with, or much influenced by, Rudolf Kingslake. Several people regretted not being able to prepare a paper but, nevertheless, sent greetings and wishes to Rudolf on his birthday. For example, Dr. Walter Mandler wrote,

During my working life as a lens designer I had numerous contacts with Dr. Kingslake. Two of them come to mind.

Around 1960 Eastman Kodak was purchasing a microfilm lens for the Mil. "D" Aperture that had been developed and was in production at Leitz Canada. Dr. Kingslake analyzed our design and was using his results as a basis of discussion for setting performance specifications. Despite the fact that it was my own design, I did gain additional insights from this exercise that helped me in other applications of this particular lens type.

In July 1966, immediately after the Rochester conference Lens Design with Large Computers, I met Dr. Kingslake at the house of a mutual friend. The papers on the Automatic Lens Design Problem had impressed me very much and I was somewhat subdued because I did not have access to a "large computer." In our informal discussion of the convention papers (there were two more lens designers present) Dr. Kingslake outlined the limitations of automation and pointed to the importance of the designer's choice of a starting configuration. He was of the opinion that this might not have been sufficiently emphasized because the topic of the convention lay in another area. Even today with attempts at "global optimization" the choice of a starting configuration is well worth the lens designer's time and effort.

\section{The Kingslake Team}

While Rudolf and Hilda Kingslake have each made their own special and very individual contributions to our field, I still think of them as a team. Ten years ago I had the privilege and honor to say some words at a special banquet and retrospective honoring Rudolf and Hilda Kingslake for their careers in optics as lens designers, authors, and educators. This banquet was held at the Del Coronado Hotel in San Diego during an SPIE annual meeting.
In celebration of Rudolf's nearly 70 years of contributions I would like to repeat-this time in print-my remarks.

I could not be more pleased and honored than to have been selected to say a few words in recognition of my good friends - and indeed your good friends-Hilda and Rudolf Kingslake.

I am here to represent, however inadequately, all the component parts of the Kingslakes' international family, which includes colleagues in optical engineering from around the world, coworkers at the University of Rochester and at Kodak, present and former students, as well as all those special students who have attended courses not only in this country but also in other parts of the world, and finally all those who have benefited from their individual and joint writings, as well as from their personal friendship and concern.

Both Hilda and Rudolf, in their usual modest way, were very concerned that nobody knew enough about them to take on this task that I had been assigned. I assured them not to worry because I had been chosen with the full knowledge that I often gave papers at meetings on topics that I didn't know anything about.

As you know, this particular time has been chosen to celebrate Hilda's and Rudolf's joint contributions since it coincides with Rudolf's 80th birthday, which is actually on Sunday. Naturally, we are much too genteel a society to mention Hilda's birth date!

One thing that we all enjoy about the Kingslakes is their dry sense of humor. My wife was asking Rudolf yesterday about the celebration of his 80 th birthday. He responded that there was nothing very special about 80 , after all, anyone can have an 80th birthday, all they have to do is to live long enough!

Another example of their humor is their comment on the metric system for everyday use: "There is nothing wrong with the metric system, but it is a pity that the centimeter isn't about an inch long."

Both Hilda and Rudolf were educated at Imperial College in the optics program that started in 1917. Hilda was one of three students in the first regular undergraduate class in 1920 , and Rudolf was one of four students in the second regular class in 1921 . They both graduated with their de- 
grees, and Rudolf went on to get an M.S. degree in 1926 and a D.Sc. in 1950.

I must say that Rudolf showed his exceptional good sense in marrying Hilda in 1929, not only because she was and is a splendid person and was a colleague in optics-indeed, a senior colleague-but also because she was the daughter of Professor Conrady, who taught lens design at Imperial College. I can in no way fault Hilda's choice of spouse either, although I understand from Rudolf that Professor Conrady had something to say on that topic. Thus were their joint careers launched that have already spanned more than 50 years, and they have many projects still under way.

We in this country owe a debt to Dr. Rush Rhees, who was president of the University of Rochester in the 1920s. He recognized the proven strength and future potential of Rudolf. He reported to the trustees, "I have been fortunate in finding a man ideally trained for geometrical and optical design ... he has published eight papers ... and by training and experience he is admirably fitted to contribute largely to the development and significance of our new enterprise." That new enterprise was, of course, The Institute of Optics.

The Board of Trustees confirmed Rudolf's appointment as assistant professor on June 15, 1929. Rush Rhees was a very astute man; while the formal records are silent on the issue, I am sure that he knew that he was getting a package deal since Hilda had already three years of industrial experience and had published several papers!

Rush Rhees was, however, concerned about one significant weakness that the Kingslakes exhibited, and that was their comparative youth, for example, Rudolf was only 26. However, Rush Rhees correctly argued that this was a weakness that they would undoubtedly grow out of! And, as Walter Cronkite would say, "the rest is history," and I must add, history is still very much in the making.

Rudolf's technical papers, books, patents, and contributions to standards are well known to us and have contributed to all our individual education and growth in optical engineering. He is currently at work on a new book that is soon to be published.

Hilda is perhaps best known for her knowledge and writings in the organizational history of our field, particularly the 50-year history of the Optical Society of America and the 50-year history of The Institute of Optics. She also has made significant contributions to the world's literature in optics and related fields. I understand that she still receives requests for reprints of a paper published by the Royal Photographic Society in 1926.

Their joint writings are also extensive and include such diverse topics as "A new refractometer for the near infrared," published in the Journal of the Optical Society of America in 1937; "Alexander Eugene Conrady," published in Applied Optics in 1966; and "The contributions of optics to modern technology and a buoyant economy," published in Optica Acta in 1968.

They have both been honored many times by professional societies and by universities and the community at large. I will refrain from giving a long list of these honors. I remember once at a meeting a chairman introduced Rudolf with a rather long and detailed resumé of his achievements. Rudolf's response was to thank the chairman for "that introduction of almost obituary fullness!"

We do applaud their joint and individual technical contributions, but most of all, we applaud them for just being who they are.

\section{Kingslake Medal and Prize}

It is very appropriate that this is the issue in which we recognize the recipient of the Kingslake Medal and Prize for the best paper published in Optical Engineering during 1992. The Kingslake Award Committee consisted of Satoshi Ishihara, chair; Jean Bulabois; and Bruce Steiner. The medal and prize for 1992 is being awarded to Aden B. Meinel and Marjorie P. Meinel for their paper entitled "Two-stage optics: high-acuity performance from low-acuity optical systems."

May we all congratulate the Meinels for this well-deserved award. The award committee wrote that "the paper presents two-stage optics as a very powerful solution to a hard problem: correction of wavefront errors of large telescopes on the ground and even in space. This solution both lowers the manufacturing cost and enables deployment of a large telescope. This paper is very good technically: it provides nice, complete explanations and a successful experimental demonstration. The wording is precise and very well illustrated with a large number of clear figures. Moreover it can be read by many engineers or technicians without special training in the field and, therefore, is of general utility."

\section{Rudolf Kingslake Medal and Prize-Past Recipients}

1974 Irving R. Abel and B. R. Reynolds

1975 J. M. Burch and C. Forno

1976 Richard E. Swing

1977 David B. Kay and Brian J. Thompson

1978 Norman J. Brown

1979 J. R. Fienup

1980 G. Ferrano and G. Hausler

1981 Robert A. Sprague and William D. Turner

1982 David M. Pepper

1983 James R. Palmer

1984 Gene R. Gindi and Arthur F. Gmitro
1985 Armand R. Tanguay, Jr.

1986 Arthur D. Fisher, Lai-Chang Ling, John N. Lee, and Robert C. Fukuda

1987 Chris P. Kirk

1988 Ares J. Rosakis, Alan T. Zehnder, and Ramaratnam Narasimhan

1989 Pochi Yeh, Arthur Chiou, John Hong, Paul H. Beckwith, Tallis Chang, and Monte Khoshnevisan

1990 Paul R. Prucnal and Philippe A. Perrier

1991 Brian E. Newnam 
With this award the Meinels add further luster to their careers and to the list of winners of the Rudolf Kingslake Medal and Prize.

\section{Postscript}

I would like to conclude by quoting from the preface that Professor Nicholas George and I wrote for the 50-year history of The Institute of Optics at the University of Rochester.

Somewhere along the path through life, each of us probably has met some special person who is a constant inspiration and a treasured friend. Those of us at The Institute of Optics this evening are privileged to know two such people-Hilda and Rudolf Kingslake. They embody all the qualities one hopes to find in one's colleagues-scholarship, industry, and dedication. But more than this, they are warm, gentle people, devoted to the good of students, the good of the community, and the furtherance of optical engineering. The history of the field of optics itself has been shaped and continues to be shaped by the contributions for this unique and beloved couple.

\section{Special Section-Display Technologies}

In addition to the special tribute to Rudolf Kingslake, this issue also includes eight expanded and reviewed papers that were originally presented at the SPIE conference on Display Technologies held in December 1992 in Taiwan. I would like to thank Dr. Shin-Tson Wu of Hughes Research Laboratories for acting as the guest editor for this special section.

Brian J. Thompson Editor

1. Hilda G. Kingslake, The First Fifty Years, The Institute of Optics, 1929-1979 (1979).

\section{Guest Editor's Remarks}

In sending out invitations to contributors for this issue it was stressed that in his writings Rudolf Kingslake had shown an appreciation for the artistry that was at one time the hallmark of lens design. When so-called "automatic design" computer programs made their appearance about 30 years ago it seemed that this would be a thing of the past. In a review of a book I wrote, Kingslake said, "In today's computer age the main trend of lens designs is, unfortunately, to ignore our laboriously acquired knowledge of geometrical optics and substitute for it the mathematical problem of optimizing a merit function by varying a large number of design parameters," and "there is a good prospect that in a very few years this will become the principal activity of lens designers."

Over the intervening years the fears of an older generation and the hopes of a younger generation have not been completely realized.

The mathematical difficulties of the early years have been largely overcome, but one outstanding feature is shared by all systems. Because of the nonlinearity of the expressions for ray intercepts or wavefront deformations, the solutions of the equations, which are meant to predict the required changes in design parameters, are restricted to those that lie in the neighborhood of the starting point. In addition, it becomes a matter of crucial performance to define a suitable set of rays to be traced and to assign to them the appropriate set of weighting factors. None of these parameters is selfevident, particularly when a new type of lens design is required to meet modern requirements such as a zoom lens operating in the near and far infrared, for example.

Current emphasis is on the development of techniques that will search for a "global minimum," making full use of the computing speed of even moderately priced PCs. This is the central theme of the papers in this issue. Rather than dealing in detail with specific techniques of design they present a number of views on the matter in the hope that from them will emerge a program of lens design that will provide total optimum results without too much intervention on the part of a human designer.

If this comes to pass, it will remove much of the artistry that still survives in lens design, even after 30 years of "automatic design." If I may make a personal remark, speaking as a veteran of the golden age of lens design, I do not believe that this will happen in the near future unless some radical breakthrough takes place that is not yet on the horizon. The artistry that Kingslake recognized will survive.

Arthur Cox Guest Editor 
September 1993

Optical Science and Engineering in Canada C.P. Grover

National Research Council

Institute for National Measurement Standards

Ottawa, Canada K1A OR6

613/993-2098 • 613/952-1394 FAX

October 1993

Microlithography

James R. Sheats

Hewlett-Packard Company

3500 Deer Creek Road

Palo Alto, CA 94304-1392

415/857-5987 • 415/857-2379 FAX

Optical Engineering in Hungary

Tivadar Lippenyi

HUNGOPTIKA

Tartsay u. 24

Budapest H-1120, Hungary

$3611563985 \cdot 3611563985$ FAX

Zoltan Fuzessy

Technical Univ. Budapest

Department of Physics

Balazs Bela u.36.IV.8.

Budapest H-1094, Hungary

$3611666361 \cdot 3611666808$ FAX

\section{November 1993}

Acquisition, Tracking, and Pointing

Mohammed A. Karim

University of Dayton

Center for Electro-Optics

300 College Park

Dayton, Ohio 45469-0227

$513 / 229-2241 \cdot 513 / 229-3433$

\section{December 1993}

Magnetospheric Imagery and

Atmospheric Remote Sensing

Supriya Chakrabarti

Boston University

Center for Space Physics

725 Commonwealth Avenue

Boston, MA 02215

E-mail: supc@bu-ast.bu.edu

617/353-5990 • 617/353-6463 FAX

January 1994

Infrared Technology

Marija S. Scholl

Alenka Associates

P.O. Box 27408

Tempe, AZ 85285-7408

E-mail: msscholl@aol.com

602/491-7814

\section{February 1994}

Optical Interconnects and Packaging

Sing Lee

University of California/San Diego

E\&CE Department

La Jolla, CA 92093-0407

619/534-2413 • 619/534-1225 FAX

\section{March 1994}

High Heat Flux Optical Engineering

Ali M. Khounsary

Argonne National Laboratory

Advanced Photon Source, APS 362

Argonne, IL 60439

$708 / 252-3384$ • 708/252-3222 FAX
April 1994

Optical Pattern Recognition

Joseph L. Horner

Rome Laboratory

EROP

Hanscom AFB, MA 01731-5000

617/377-3841 $617 / 377-5041$ FAX

Bahram Javidi

University of Connecticut

School of Engineering

Department of Electrical and Systems

Engineering

Room 312, U-157

260 Glenbrook Road

Storrs, CT 06269-3157

203/486-4816 • 203/486-3789 FAX

Manuscripts due Sep. 1, 1993.

May 1994

Semiconductor Infrared Detectors

Antoni Rogalski

Military Technical Academy

Institute of Technical Physics

Kaliskiego St. 25

01-489 Warsaw 49, Poland

$4822369109 \cdot 4822362254$ FAX

Manuscripts due Oct. 1, 1993.

June 1994

Optical Science \& Engineering in India

Rajpal S. Sirohi

Indian Institute of Technology

Applied Optics Laboratory

Physics Department

Madras-600 036, India

044-2351365 ext. $221 \cdot 044-2350509$ FAX

Manuscripts due Nov. 1, 1993.

July 1994

Adaptive Wavelet Transforms

Harold H. Szu

U.S. Navy

Naval Surface Warfare Center

Code R44

10901 New Hampshire Avenue

Silver Springs, MD 20903-5000

301/394-3097 • 301/394-3923 FAX

Manuscripts due Dec. 1, 1993.

August 1994

Digital Image Recovery and Synthesis

Paul S. Idell

Air Force Phillips Lab.

PL/GPOA

390 B Great Road, \#18

Acton, MA 01720

612/377-3663 • 617/377-3661 FAX

Manuscripts due Dec. 1, 1993.

September 1994

Optics in South Africa

Hannes Markusse

ELOPTRO

Institute of Atomic Physics

P.O. Box 869

Kempton Park 1620, South Africa

Maurice W. McDowell

CSIR/Production Technology Div.

Productiontek

P.O. Box 395

Pretoria 0001, South Africa

$27128413418 \cdot 27128412131 \mathrm{FAX}$

Manuscripts due Jan. I, 1994.
October 1994

Optics in Russia

V. Ya. Panchenko

Scientific Research Center for Technological

Lasers

Russia Academy of Sciences

B-333, Gubkina, 3

117971 Moscow, Russia

E-mail: ilc@ compnet.npimsu.msk.su (095)135-54-30 • (095)334-02-01 FAX

Manuscripts due March 1, 1994.

November 1994

Micro-Optics

Chandrasekhar Roychoudhuri

University of Connecticut at Storrs

Photonics Research Center

MS-157, Room 312

260 Glenbrook Road

Storrs, CT 06269-3157

203/486-4816 • 203/486-3789 FAX

Manuscripts due April 1, 1994.

December 1994

Optics in Ireland

John Hegarty

C. D. Hussey

University of Dublin

Trinity College

Department of Pure and Applied Physics

Dublin 2, Ireland

+353-1-7022019 • +353-1-711759 FAX

Manuscripts due May 1, 1994.

\section{January 1995}

X-Ray/EUV Optics

Richard B. Hoover

NASA Marshall Space Flight Center

ES52 Space Science Center

Huntsville, AL 35812-0001

E-mail: hoover@ssl.msfc.nasa.gov

205/544-7617 • 205/544-5856 FAX

Manuscripts due June 1, 1994.

March 1995

Optical Engineering in Ophthalmology

Suganda Jutamulia

Kowa Company, Ltd.

Silicon Valley Office

100 Homeland Court, Suite 302

San Jose, CA 95112

408/441-9300 • 408/441-0537 FAX

Toshimitsu Asakura

Hokkaido University

Research Institute for Electronic Science

Sapporo, 060 Japan

81-11-716-2111 • 81-11-758-3173 FAX

Manuscripts due Aug. 1, 1994.

April 1995

Optics in the Ukraine

Oleg V. Angelsky

Chernovtsy University

Department of Correlation Optics

2 Kosyubinsky Street

274012 Chernovtsy

Ukraine

(03722) 44730 • (03722) 41314 FAX

Manuscripts due Aug. 15, 1994 